\title{
Subjecting the Catalog to Tagging
}

\author{
Luiz H. Mendes \\ Jennie Quiñonez-Skinner \\ Danielle Skaggs
}

\begin{abstract}
Purpose - The purpose of this paper is to present the implementation of LibraryThing for Libraries (LTFL) in an academic library and analysis of usage of LTFL data and its potential for resource discovery in the catalog.

Design/methodology/approach - The paper reviews the literature on social tagging and incorporation of third-party user-generated metadata into the library catalog. Provides an assessment based on the analysis of total absolute usage figures and frequency of use of LTFL data.

Findings - Based on the data available, usage of LTFL data in the catalog is low, but there are several possible contributing factors identified.

Originality/value - The paper contributes to the literature on the implementation of LTFL in an academic library and provides usage statistics on LTFL data. Provides directions for future research about tagging in the catalog.

Keyword(s): Online catalogues; Tagging; Subject headings; Web 2.0; Libraries

Article Type: Technical Paper
\end{abstract}

\subsection{Introduction}

There have been a number of developments and implementations in the use of Web 2.0 technologies to facilitate resource "discovery and delivery" as well as information organization. One implementation is the incorporation of LibraryThing tags_LibraryThing for Libraries (LTFL) - into the library catalog. As a cataloging application, LibraryThing provides three features: tag clouds (user-generated subjects), links to other editions and translations of a work (FRBR-like links to related works), and recommendations to similar books. Tags (tag clouds) in the catalog certainly provide an additional option for "resource discovery" for users through browsing the tags, but they also create a bridge from the users' vernacular to the controlled vocabularies, enhance the existing metadata in bibliographic records, as well as establish relationships to related works. The focus of this article is to present an implementation of LibraryThing for Libraries in the catalog and an assessment and analysis of tagging the catalog. 


\subsection{Libraries, Web 2.0, The Catalog: An overview}

The development of social software tools brought a revolution in thought to libraries. The library catalog, or online public access catalogs (OPACs) entered center stage in the debate-both the future of the catalog and cataloging have generated heated discussions within the profession. The development of Web 2.0 applications, especially social bookmarking and tagging tools (Hammond et al., 2005; Macgregor and McCulloch, 2006) led to the re-thinking of how libraries and library services could (and should!) change in this new environment. New discovery tools, talks of next-generation catalogs, and adoption of social features similar to those in the Web (e.g., Amazon.com) such as the ability of users to comment, review, and tag resources led libraries to incorporate many of these social technologies to foster social and user participation. Central to the concept of Web 2.0-or, Library 2.0- was the push to make OPACs more like a "social tool" where it would provide for user participation for content creation and sharing such as reviews, recommendations, and tagging. The focus was to transform the OPAC from a static system difficult to use to a more open interactive application. Some would argue that little progress has been made here and that the perception that the "OPAC sucks" still holds true. In her overview of the issues related to the library catalog in the 2.0 environment, Coyle (2007) calls most library catalogs "un-social." (p. 290)

The emergence of social tagging is often attributed to the creation of Del.icio.us (http://del.icio.us/), a social bookmarking site where users can organize, tag, and share Web sites, and Flicker (www.flickr.com/), a photograph-sharing site where users organize, tag and share photographs. Although tagging became a popular phenomenon in 2003, there have been recent innovations and new trends continue to evolve (Smith, 2008).

There have a been a number of recent implementations of tagging in library catalogs: PennTags (http://tags.library.upenn.edu/) is the University of Pennsylvania site that allows users to tag electronic resources (Web sites, articles) and records in the library catalog; Ann Arbor District Library (www.aadl.org/sopac/tagcloud) implemented a social library catalog (SOPAC); University of Michigan developed the tagging tool MTagger (www.lib.umich.edu/mtagger/) which also allows users to tag records in the catalog; and Darien Library in Connecticut recently launched its SOPAC 2.0 (http://www.darienlibrary.org/catalog) which allows users to add content such as comments, reviews, ratings, and tags to catalog records.

These implementations attempt to redefine the catalog in the Web 2.0 environment, an attempt to move the catalog from an OPAC to a SOPAC_- "social OPACs" (Furner, 2007).

\subsection{Subject Headings and Tagging: Some issues}


The debate between social tagging and traditional classification systems as well as comparisons between the characteristics and use of controlled and uncontrolled vocabularies have been extensively covered in numerous forums (Guy and Tonkin, 2006; Mathes, 2004; Macgregor and McCulloch, 2006; Spalding, 2008; Spiteri, 2006; Weinberger, 2005). Comparisons between the structure of tags and controlled vocabularies (e.g., Library of Congress Subject Headings, LCSH) have also engendered a great debate about the advantages and disadvantages of tagging and controlled vocabularies; the purpose of controlled vocabularies and social tagging; the differences between tags and subject headings; and whether tags are better than subject headings.

Definitions for tagging, social tagging, folksonomy, and controlled vocabularies abound in the literature. Here are some definitions provided by Baca (2008):

controlled vocabulary: An organized collection of words, phrases, and/or names, structured to show the relationships between terms and concepts. A controlled vocabulary is usually limited to a particular domain or set of concepts, and designates a preferred form or heading for each concept, person, or entity represented.

folksonomy: An assemblage of concepts, represented by terms and names (called "tags"), the result of social tagging. Note that a folksonomy is not a taxonomy.

social tagging: The decentralized practice and method by which individuals and groups create, manage, and share terms, names, etc. (called "tags") to annotate and categorize digital resources in an online "social" environment. A folksonomy is the result of social tagging. Also referred to as collaborative tagging, social classification, social indexing, mob indexing, folk categorization.

tagging: In the context of the Web, the act of associating terms (called "tags") with an information object (e.g. a Web page, an image, a streaming video clip), thus describing the item and enabling keyword-based classification and retrieval. Tags - a form of usergenerated metadata - from communities of users can be aggregated and analyzed, providing useful information about the collection of objects with which the tags have been associated.

The difference between "tags" and controlled vocabularies can be reduced to the authoritative, structured information of controlled vocabularies and the unstructured characteristics of the tags which are not hierarchical and do not capture relationships between terms, do not control for homonyms, synonyms and are often ambiguous, imprecise, and personal. Common problems observed with tags include misspelled forms, compound words strung together, variation in the use of singular and plural forms, and the inclusion of personal tags ("to read") (Golder and Huberman, 2006; Guy and Tonkin, 2006; Mathes, 2004). Problems related to "precision" and "recall" as well as personal information organization (a benefit of tagging) versus collocation 
(the benefit of subject cataloging) have also been discussed. Despite these problems, some see the benefits of social tagging services as creating "the kinds of environments in which we can evolve metadata vocabularies in a natural way" (Guy and Tonkin, 2006); others see the promise of improving resource discovery of library resources (Furner, 2007).

The issue of leveraging metadata from third-party publishers, vendors, and content creators is not new for libraries. Catalogs are populated by records created by third parties. Digital libraries include many resources described and tagged (keywords assigned) by the content creator. The difference with tagging is that the tags are assigned by users (i.e., user-generated metadata $v$. content-creator generated metadata).

Unlike the opening of the catalog to tagging, many libraries are harnessing metadata from a Web 2.0 application with the implementation of LibraryThing for Libraries (LTFL).

\subsection{LibraryThing for Libraries}

LibraryThing for Libraries (LTFL) is a service that displays user-generated metadata from the "social-cataloging site" LibraryThing (http://www.librarything.com/) in an individual library's catalog (LTFL, 2008). The LTFL data consists of three types: tags, recommendations, and links to other editions and translations of works.

Research has shown that individual tags in social tagging sites such as del.icio.us can be categorized into seven types, some of which are "generally meaningful" (identifying the topic) and those which are of personal use only (Golder and Huberman, 2006). Tags in LibraryThing, another social tagging site, include both generally meaningful and personally useful. Currently, LibraryThing has 41 million tags assigned to 32 million books. The tags displayed by LTFL, however, go through a screening process, which excludes tags for explicitly personal use such as "to read" or "gift from mom" (LTFL, 2008). When displayed in the library catalog, the tags appear as a tag cloud, with increasing font size and weight indicating increasing frequency of tag use.

When a user clicks on a tag in a catalog record, LTFL's tag browser opens in a lightbox -the smaller tag browser window appears on top of the already open catalog record, with the catalog record darkened to draw the user's eye to the tag browser (see Figure 1). The right side of the tag browser displays books that have been tagged with the selected tag, all of which are owned by the library. Clicking on a book's title from this display closes the lightbox and takes the user to the selected book's catalog record. The left side of the tag browser displays the current book's tags as well as tags related to that tag, any of which can be chosen; the books displayed on the right hand side change to match the selected tag. In the upper right of the tag browser is the tag search box, which allows users to search through LTFL tags. If no tag exactly matches the search 
term entered, no tags are returned; however, as long as one book was tagged with the search term, some corrections and user guidance are provided by the related tags.

\section{TAKE IN: Figure 1 \\ CAPTION: Tag browser in lightbox display.}

LTFL recommendations, called similar books, are not solely based on user-generated metadata from LibraryThing; both "subject headings and call numbers" play into LTFL's recommendations (LTFL, 2008). Recommended books listed include only those books owned by the library, and are reached by clicking on the book's title.

The final type of metadata provided, links to other editions and translations, provide FRBR-like links between different editions of a work. These connections between differing editions of a work are user-generated and based on the ISBNs in the user's collection, making links to rarer ISBNs that may not be in LibraryThing users' collections less likely.

\subsection{Implementing LTFL}

LTFL is ISBN-driven. A library implementing LTFL first creates a LTFL account and exports the ISBNs of records in its collection and uploads the list to its LTFL account page. While at the LTFL account page, using a configuration widget provided by LTFL, each library can configure how the LTFL metadata will be displayed in their catalog. Finally, the library exports the required code to have the LTFL data appear in the catalog and then must add this code to the catalog's template page in the desired location. To keep the LTFL data up to date, ISBN data for new acquisitions must be periodically exported and uploaded to LTFL. Step-by-step instructions on implementing LTFL are available at http://www.librarything.com/wiki/index.php/LTFL:Installation_instructions.

Since LTFL data is not directly added to the catalog record, and is instead displayed by means of javascript, LTFL data can take a moment to appear once the book's catalog record displays. Also, the tags aren't indexed by the catalog, so the only way to search through LTFL tags is through the tag browser.

Since the announcement of LTFL in April 2007

(http://www.librarything.com/thingology/2007/04/sneak-peek-librarything-for-libraries_09.php), 68 libraries have implemented LTFL

(http://www.librarything.com/wiki/index.php/LTFL:Libraries_using_LibraryThing_for_Libraries). The majority of these libraries are public libraries, with only 25 academic libraries and academic library consortia implementing LTFL as of September 2008. Not surprisingly given this timeframe, very little has been published about the implementation and user experience with 
LTFL at these libraries, particularly for academic libraries; what has been written involves the implementation of LTFL at Danbury Public Library (Blumenstein, 2007 \& Sheehan, 2007). Some information about San Francisco State University's implementation of LTFL, including a detailed description of the setup process, has been presented by Wenzler (2007).

\subsection{CSUN Implementation of LTFL}

In an effort to increase resource discovery, the Oviatt Library at California State University, Northridge (CSUN) became the 29th library using LTFL with its implementation in March 2008. The Library Systems Administrator was responsible for the implementation process with the library's technology committee providing advice on how to display the data. Like many other academic libraries, CSUN chose to display LTFL data at the bottom of the catalog record (see Figure 2). The other common location for LFTL data, used by four academic libraries, is on the right hand side of the catalog record (see Figure 3).

\section{TAKE IN: Figure 2}

CAPTION: Record with LTFL data at the bottom from CSUN library catalog (http://suncat.csun.edu/record=b2130012)

\section{TAKE IN: Figure 3 \\ CAPTION: Record with LTFL data on right, from SFSU library catalog (http://opac.sfsu.edu/search/i0670839531)}

CSUN exported 471,885 distinct ISBNs, and found that LibraryThing had data for $46 \%$ of these ISBNs. LTFL does not provide standard "overlap" percentages for academic libraries, but the current standard overlap for public libraries is approximately 65\% (LTFL, 2008).

With the goal of the LTFL implementation to improve resource discovery through tags using user-generated vocabulary, recommendation links, and FRBR-like other editions, and without published or anecdotal evidence of LTFL's effectiveness at academic libraries, an analysis of LTFL use at CSUN became important. One measurement of use available was the usage statistics provided by LTFL (available for export on the library's LFTL account page), which is the basis for the assessment and analysis presented here.

\subsection{Assessment and Analysis}

\subsection{LTFL Usage Data}


This analysis looked at 170 days of usage data, for the period of 3/11/08 to 9/1/08. Raw usage data from LTFL is reported on a daily basis for several metrics, without summary statistics. Total numbers for CSUN were compiled, along with average and median daily figures (see Table 1).

Table 1. LTFL usage statistics for CSUN

\begin{tabular}{|c|c|c|c|}
\hline & Total & Average & Median \\
\hline Catalog pages viewed & 262,322 & 1543 & 632.5 \\
\hline $\begin{array}{l}\text { Pages viewed with an associated } \\
\text { ISBN }\end{array}$ & 194,349 & 1143 & 598 \\
\hline Pages with LTFL data displayed & 130,684 & 769 & 536 \\
\hline $\begin{array}{l}\text { Pages with LTFL } \\
\text { recommendations }\end{array}$ & 77,604 & 456 & 301.5 \\
\hline $\begin{array}{l}\text { Times LTFL recommendations } \\
\text { links were followed }\end{array}$ & 1,522 & 9 & 5 \\
\hline Pages with LTFL other editions & 14,888 & 88 & 59.5 \\
\hline $\begin{array}{l}\text { Times LTFL other editions links } \\
\text { were followed }\end{array}$ & 214 & 1 & 1 \\
\hline Pages with LTFL tags & 127,872 & 752 & 531 \\
\hline $\begin{array}{l}\text { Times the tag browser was } \\
\text { displayed }\end{array}$ & 1,292 & 8 & 5 \\
\hline $\begin{array}{l}\text { Times a link to a book in the tag } \\
\text { browser was clicked on }\end{array}$ & 670 & 4 & 2 \\
\hline $\begin{array}{l}\text { Tags clicked on and/or tag } \\
\text { searches performed in the tag } \\
\text { browser }\end{array}$ & 1596 & 9 & 6.5 \\
\hline
\end{tabular}

Nearly half of all pages viewed during this time period had LTFL data displayed, with the percentage increasing when considering only those pages that had ISBN data $(67.2 \%$ for the latter versus $49.8 \%$ for the former). LTFL tags were the most common type of LTFL data displayed (available on $97.8 \%$ of all pages viewed with LTFL data), followed by recommendations data (available on $59.4 \%$ of all pages viewed with LTFL data), and trailed by other editions data (available on $11.4 \%$ of all pages viewed with LTFL data). See Table 2 for additional prevalence and usage percentages.

Although tag data was far more abundant, in usage both tags and recommendations were similarly popular. In terms of actual usage, tags were clicked an average of 8 times a day while recommendations were clicked an average of 9 times a day; both data types had a median value of 5 per day. This equality remains when considering use as a percentage of pages with corresponding LTFL data available: users clicked on tags on $1.0 \%$ of pages with LTFL tags 
available and clicked on recommendations on $2.0 \%$ of pages with LTFL recommendations available. Though LTFL other editions were displayed substantially less often in absolute terms (available on average for 88 pages viewed each day), other editions usage was similar to other LTFL data types when considering other editions use as a percentage of pages with other editions data available; users clicked on other editions on $1.4 \%$ of pages that had other editions available.

Table 2. Prevalence and usage figures for LTFL data

\begin{tabular}{|c|c|c|}
\hline \multicolumn{3}{|c|}{ Overall prevalence of LTFL data } \\
\hline- & Total pages viewed that had LTFL data & $49.8 \%$ \\
\hline & Total pages with ISBN data that had LTFL data & $67.2 \%$ \\
\hline \multicolumn{3}{|c|}{ LTFL tag prevalence and usage } \\
\hline- & Total pages viewed that had LTFL tags & $48.7 \%$ \\
\hline & Pages with LTFL data that had LTFL tags & $97.8 \%$ \\
\hline & Total pages viewed where user clicked on LTFL tag ${ }^{1}$ & $0.5 \%$ \\
\hline & Pages with LTFL tags where user clicked on LTFL tag ${ }^{1}$ & $1.0 \%$ \\
\hline & $\begin{array}{l}\text { User who clicked on a LTFL tag followed a link to a book from tag } \\
\text { browser }\end{array}$ & $51.9 \%$ \\
\hline & $\begin{array}{l}\text { Average number of clicks on tags and/or tag searches each time the } \\
\text { tag browser opened }\end{array}$ & 1.2 \\
\hline \multicolumn{3}{|c|}{ LTFL recommendations prevalence and usage } \\
\hline & Total pages viewed that had LTFL recommendations & $29.5 \%$ \\
\hline- & Pages with LTFL data that had LTFL recommendations & $59.4 \%$ \\
\hline- & Total pages viewed where user clicked on LTFL recommendation ${ }^{2}$ & $0.6 \%$ \\
\hline & $\begin{array}{l}\text { Pages with LTFL recommendations where user clicked on LTFL } \\
\text { recommendation }{ }^{2}\end{array}$ & $2.0 \%$ \\
\hline \multicolumn{3}{|c|}{ LTFL other editions prevalence and usage } \\
\hline & Total pages viewed that had LTFL other editions & $5.7 \%$ \\
\hline- & Pages with LTFL data that had LTFL other editions & $11.4 \%$ \\
\hline- & Total pages viewed where user clicked on LTLF other editions ${ }^{3}$ & $0.1 \%$ \\
\hline 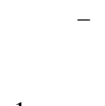 & $\begin{array}{l}\text { Pages with LTFL other editions where user clicked on LTFL other } \\
\text { editions }{ }^{3}\end{array}$ & $1.4 \%$ \\
\hline \multicolumn{3}{|c|}{${ }^{1}$ Given clicking on one tag per page } \\
\hline \multicolumn{3}{|c|}{${ }^{2}$ Given clicking on one recommendation per page } \\
\hline${ }^{3} \mathrm{Giv}$ & clicking on one other edition per page & \\
\hline
\end{tabular}

\subsection{Comparing LCSH and LTFL tags}


In the second level of the assessment, a sample of twenty-one (21) non-fiction books from the New York Times' Best Seller List were selected for a comparison of LCSH and LTFL tags within the library catalog. All titles selected are cataloged by CSUN and tagged by LibraryThing users. Data from each title was gathered and analyzed using descriptive statistics (mean and median) including the following: the number of titles accessible through LCSH; the number of titles accessible through LTFL tags; and the number of LCSH headings assigned to each title.

As expected, the number of LCSH headings assigned varied from record to record. The books in the sample had an average of 4.1 subject headings each with a median of 4 . The number of LTFL tags displayed in the catalog was set by the System Administrator and can be changed. For this implementation of LTFL, CSUN decided to display a maximum of 15 tags per book, which can be increased to display a maximum of 30 tags. Both LCSH and LTFL tags are presented to the user as hyperlinks, and these links lead to the discovery of new books that may or may not be relevant to the user's search.

After calculating the total number of books available through a subject heading (LCSH) and an LTFL tag, the mean was respectively 379 (median 191) and 1,478 (median 1,314). The standard deviation is higher for LCSH because the sample size is small and there is a larger variation in the number of subject headings assigned to each work. A larger sample size is need for a more accurate comparison between LCSH and LTFL tags in the catalog. From this data users can assume that for every new title found using LCSH, four will be found using LTFL.

Table 3. Descriptive Statistical Data for LCSH and LTFL

\begin{tabular}{llllll}
\hline & Mean & Median & Low & High & $\begin{array}{l}\text { Standard } \\
\text { Deviation }\end{array}$ \\
LCSH & 379 & 191 & 0 & 1968 & 497 \\
LTFL & 1478 & 1314 & 810 & 2027 & 330 \\
\hline
\end{tabular}

\subsection{Discussion}

\subsection{Usage Data}

Overall use of LTFL data was low, remaining in the 1\%-2\% range even when considering only those pages that had LTFL data available. Usage may be low, however, due to the time period covered by this analysis. The data begins with the initial implementation of LTFL on March 11, 2008 so many users were not initially aware of this new feature in the catalog; no formal promotion campaign for LTFL was conducted. The time period analyzed also included the 
traditionally lower-use periods of spring break, semester breaks, and summer terms (May 17 August 24), and ends with data covering the three-day Labor Day holiday weekend.

The placement of the LTFL data in the catalog, at the bottom of the catalog record, may also have contributed to low usage. Users with the common screen resolution of $1024 \times 768$ or lower would have to scroll down to view LTFL data, and many of them may not have taken the time to scroll down and view the entire record (Nielson, 2006).

LTFL usage data provided only quantitative data such as the total number of tags, recommendations, and other editions clicked. There was no way to determine whether this data was one user clicking on multiple tags or recommendations from a single catalog record or whether only one tag or recommendation was selected per page (the assumption used in the analysis in Table 2 for simplicity given the lack of information on user behavior). Knowing more about user behavior would help determine whether some users have found and frequently utilize LTFL data while many users have not yet discovered LTFL data, in which case user education and promotion of the service would help improve usage, or whether many users have noticed the LTFL data but use it only rarely. In addition, having information on the number of times LCSH links are clicked over the same time period would also be helpful in determining whether users want to browse to find books, or whether they prefer to rely upon the catalog's search function for resource discovery.

\subsection{LCSH and LTFL tags comparison}

For every new book a user discovers using LCSH headings they will discover four books using LTFL. This type of data captures sheer numbers, with the potential for increased resource discovery. It does not address relevancy of additional books for users search. Based on the assumption that college users search for resources to support their topic-driven assignments, the relevancy of classification systems is critical.

The addition of user-generated metadata to catalog records, however, does enhance resource discovery, for example, for those titles lacking subject headings (e.g., works of fiction). Tags facilitate the discovery of resources by genre. Tags reflect the natural language of users and as such provide new paths for resource discovery.

\section{CONCLUSION}

This analysis revealed patterns of tag usage in the catalog as well as a snapshot of the relative potential for resource discovery using tags in comparison to LCSH. The quantitative data presented here, however, does not provide insight into user behavior and user perception of 
relevancy in the increased pool of potential sources found using tags. Some areas for further research involve direct observation of users and analysis of their behavior in the live search environment. Potential observations could focus on how many tags a user clicks and when the user decides to use tags versus LCSH links. Also of interest would be to see how many clicks users are willing to take to reach a book using tags and using LCSH links.

One other area for further research would be a comparison of libraries incorporating LTFL tags versus those libraries that have opened their catalogs for tagging. Will individual libraries be able to generate the mass of tags to compare with the critical mass of user-generated metadata from social tagging sites such as LTFL?

\section{$\underline{\text { ACKNOWLEDGEMENTS }}$}

The authors would like to thank Eric Willis, Library Systems Administrator, for providing the usage statistics analyzed in the article.

\section{$\underline{\text { REFERENCES }}$}

Baca, M. (2008). Handout for "Tag, You're it," presentation to the Los Angeles Chapter for the American Society for the Information Science "Tag, You're It: A Dialog between Social Tagging and Traditional Classification” Workshop, February 22, 2008, available at: www.lacasist.org/events/baca_handout.pdf

Blumenstein, L. (2007). “A public library tries LibraryThing,” Library Journal, available at: http://www.libraryjournal.com/article/CA6449577

Coyle, K. (2007). “The library catalog in a 2.0 world," Journal of Academic Librarianship, Vol. 33 No. 2, pp. 289-291.

Furner, J. (2007). "User tagging of library resources: toward a framework for system evaluation," paper presented at the 73rd IFLA General Conference and Council, Durban, South Africa, August 19-23, available at: www.ifla.org/IV/ifla73/papers/157-Furner-en.pdf

Golder, S.A. and Huberman, B.A. (2006). "Usage patterns of collaborative tagging systems," Journal of Information Science, No. 32 No. 2, pp. 198-208.

Guy, M. and Tonkin, E. (2006). "Folksonomies: tidying up tags?” D-Lib Magazine, Vol. 12 No. 1, available at: www.dlib.org/dlib/january06/guy/01guy.html 
Hammond, T., Hannay, T., Lund, B. and Scott, J. (2005). "Social bookmarking tools (I): a general review." D-Lib Magazine, Vol. 11 No. 4, available at : www.dlib.org/dlib/april05/hammond/04hammond.html

LibraryThing for Libraries (LTFL). (2008). LibraryThing for Libraries FAQs, available at: www.librarything.com/forlibraries/about

Macgregor, G. and McCulloch, E. (2006). "Collaborative tagging as a knowledge organization and resource discovery tool," Library Review, Vol. 55 No. 5, pp. 291-300.

Mathes, A. (2004). "Folksonomies: cooperative classification and communication through shared metadata," available at: www.adammathes.com/academic/computer-mediatedcommunication/folksonomies.pdf

Nielson, J. (2006). “Screen resolution and page layout,” available at: http://www.useit.com/alertbox/screen_resolution.html

Sheehan, K. (2007). "LibraryThing for libraries," Library Journal, available at: http://www.libraryjournal.com/article/CA6453423.html

Smith, G. (2008). "Tagging: emerging trends,” Bulletin of the Society for Information Science and Technology, Vol. 34 No.6, available at: http://www.asis.org/Bulletin/Aug08/AugSep08_Smith.pdf

Spalding, T. (2008). "The future of cataloging (as seen from LibraryThing)," paper presented at American Library Association Annual Conference, Anaheim, CA, June 29, 2008, available at: www.librarything.com/thingology/2008/07/future-of-cataloging.php (accessed 15 September 2008)

Spiteri, L.F. (2006). "The use of folksonomies in public library catalogues," The Serials Librarian, Vol. 51 No. 2, pp. 75-89.

Weinberger, D. (2005). "Tagging and why it matters," available at: http://cyber.law.harvard.edu/sites/cyber.law.harvard.edu/files/07-WhyTaggingMatters.pdf

Wenzler, J. (2007). "LibraryThing and the library catalog: adding collective intelligence to the OPAC," paper presented at the Workshop on Next Generation Libraries, California Academic Research Libraries, North Information Technology Interest Group, San Francisco, CA, September 7, 2007, available at: http://online.sfsu.edu/ jwenzler/research/LTFL.pdf (accessed 15 September 2008) 


\section{Further Reading:}

Calhoun, K. (2006), "The changing nature of the catalog and its integration with other discovery tools," report to the Library of Congress, available at: www.loc.gov/catdir/calhoun-reportfinal.pdf (accessed 15 September 2008)

Library of Congress. Cataloging Policy and Support Office. (2007). "Library of Congress Subject Headings: pre-vs. post-coordination and related issues," available at: www.loc.gov/catdir/cpso/pre_vs_post.pdf (accessed 15 September 2008)

The University of California Libraries, Bibliographic Services Task Force. (2005). "Rethinking how we provide bibliographic services for the University of California, final report: December 2005," available at: http://libraries.universityofcalifornia.edu/sopag/BSTF/Final.pdf (accessed 15 September 2008)

\section{$\underline{\text { AUTOBIOGRAPHIES }}$}

Luiz H. Mendes is the Electronic Resources Librarian at California State University, Northridge's Oviatt Library. He holds his MLIS from San Jose State University. He is a national trainer for Cataloging for the $21^{\text {st }}$ Century courses on metadata standards and applications, and cataloging electronic resources and has been actively involved in the Association for Library Collections \& Technical Services.

Jennie Quiñonez-Skinner is a reference and instruction Librarian at the Oviatt Library, California State University, Northridge. She holds her MLIS from UCLA and is actively involved in the American Library Association, ACRL, CARL, and REFORMA.

Danielle Skaggs is the Coordinator of Online Instructional Design at the Oviatt Library, California State University, Northridge. She holds her MSIS from University of Texas at Austin. She is actively involved in the American Library Association and currently serves as a member of CSU Information Literacy Digital Learning Objects Initiative Committee. 


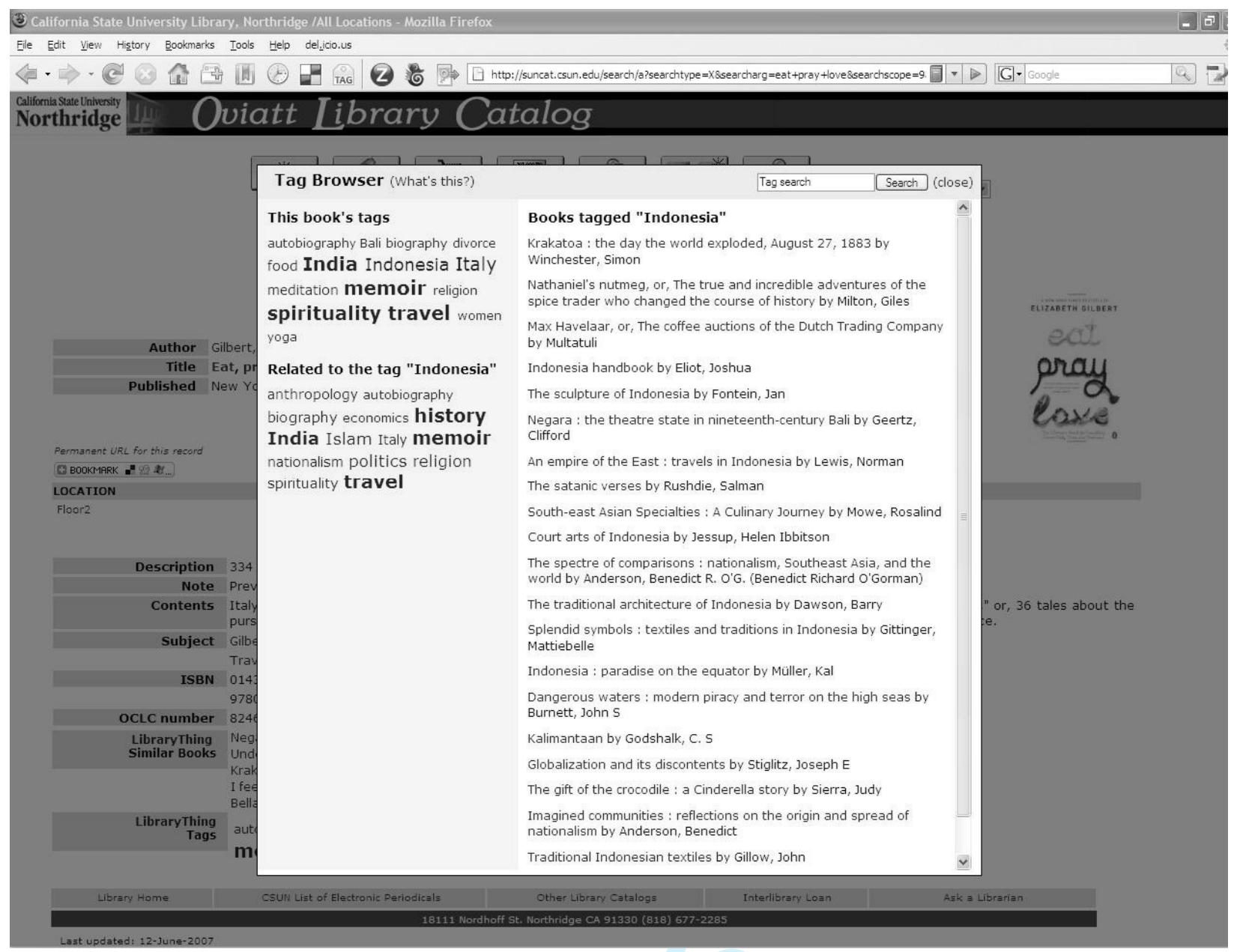




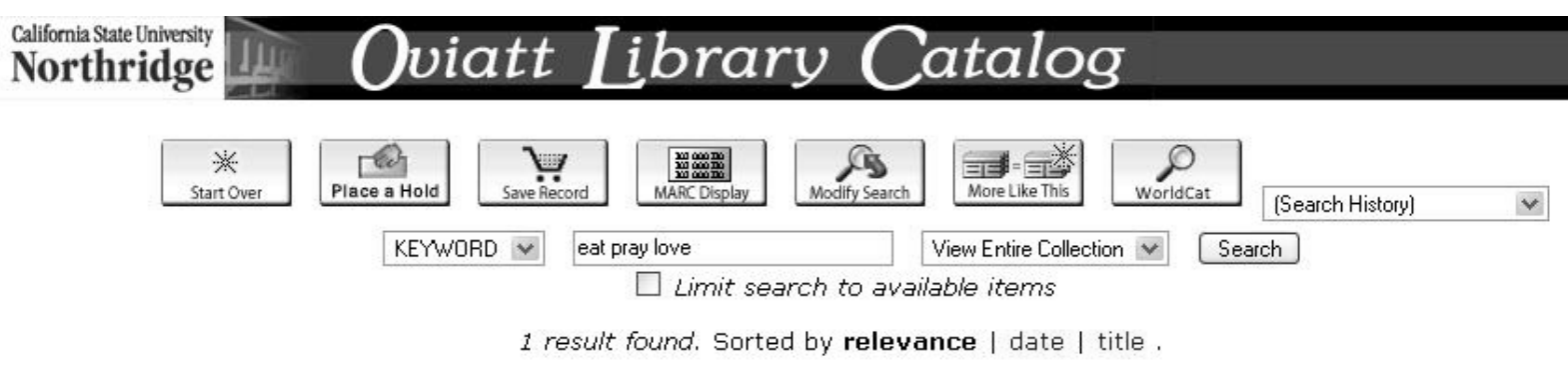

Author Gilbert, Elizabeth, 1969-

Title Eat, pray, love : one woman's search for everything across Italy, India, and Indonesia / Elizabeth Gilbert.

Published New York: Penguin, 2007, c2006.

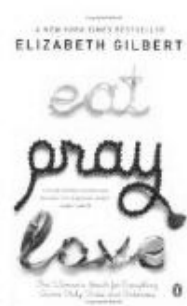

Permanent URL for this record

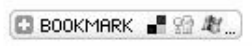

\section{LOCATION}

CALL \#

STATUS

Floor2

G154.5.G55 A3 2007

DUE 02-28-09

Description 334 p. ; $22 \mathrm{~cm}$.

Note Previously published: New York: Viking Penguin, 2006.

Contents Italy, or, "Say it like you eat it," or, 36 tales about the pursuit of pleasure -- India, or, "Congratulations to meet you," or, 36 tales about the pursuit of devotion -- Indonesia, or, "Even in my underpants, I feel different," or, 36 tales about the pursuit of balance.

Subject Gilbert, Elizabeth, 1969- -- Travel. Travel writers -- United States -- Biography.

ISBN 0143038419 (pbk.) 9780143038412 (pbk.)

OCLC number 82462742

LibraryThing Negara : the theatre state in nineteenth-century Bali by Geertz, Clifford

Similar Books Under the Tuscan sun : at home in Italy by Mayes, Frances Krakatoa : the day the world exploded, August 27, 1883 by Winchester, Simon I feel bad about my neck: and other thoughts on being a woman by Ephron, Nora Bella Tuscany : the sweet life in Italy by Mayes, Frances

LibraryThing
Tags autobiography Bali biography divorce food India Indonesia Italy meditation

memoir religion spirituality travel women yoga 


\section{InvestiGator Catalog $\mathbb{K}_{\text {Library }}^{\text {leonard }}$}

New Search | Library Account | Suggest a Purchase | Quick Contacts | Help

Databases | EReserves | ILLiad

Request
Hold

Save to Book Bag

MARC

Display

\section{Limit}

\& Sort

Another

Search Search

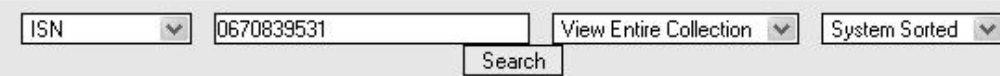

$\square$ Limit search to availabie items

Result page: $\longleftarrow$ Previous $\quad$ Next $\rightarrow$

Author King, Stephen, 1947-

Titie Needful things / Stephen King.

Pubvoate New York: Viking, 1991.

Subject Castle Rock (Me. : Imaginary place) -- Fiction.

FormGenre Horror tales.

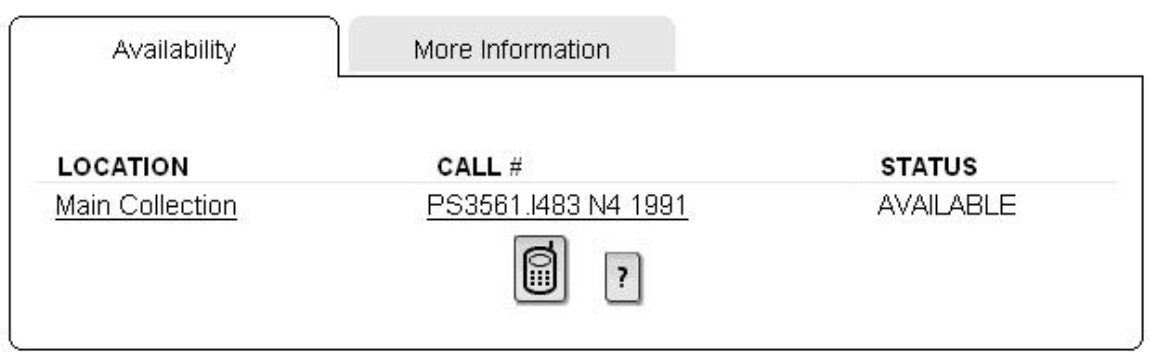

New Search | Library Account | Suggest a Purchase | Quick Contacts I Help
Libranthing Tags

Amerkat Amerkaı literatue devil fantasy

horror homor fiction King mak

nemosk waine matr podet

Stephen King supematural

suspense thriller 